\title{
Machismo: toxina que degrada o meio esportivo
}

https://doi.org/10.11606/issn.1981-4690.v35inespp71-76

Michele Schultz*

*Escola de

Artes, Ciências

e Humanidades,

Universidade de

São Paulo, São Paulo

$\mathrm{SP}$, Brasil.

\begin{abstract}
Resumo
0 machismo e a opressão contra mulheres tem sua origem engendrada na estrutura da sociedade sendo, portanto, estrutural. 0 machismo estrutural permeia as várias esferas de organização social e política, inclusive o meio esportivo. Nesse ensaio busquei trazer alguns aspectos da gênese do machismo e da violência contra as mulheres, tentando estabelecer relações com fatos vivenciados no polo aquático brasileiro. 0 cotidiano de atletas da modalidade revela um ambiente tóxico e opressor, reproduzindo a violência contra meninas e mulheres. A falta de participação de mulheres nas esferas de decisão é um fator agravante. É necessário que reconheçamos a presença do machismo estrutural no meio esportivo para pensarmos ações de combate a essa prática opressora.
\end{abstract}

PalaVRas-CHAVE: Polo aquático; Opressão; Violência; Mulheres.

\section{Introdução}

Não é de hoje que tomamos consciência do quanto o machismo - assim como o racismo está nas entranhas da nossa sociedade, o que nos permite classificá-lo como estrutural. Embora seja de difícil soluçáo por compor a estrutura, é passível de solução. Adquirida consciência coletiva da existência do machismo e seus efeitos nefastos, torna-se urgente que debatamos o tema nos vários espaços em que ele se faz presente, inclusive no meio esportivo, para pensarmos formas de eliminá-lo.

Os conceitos e preconceitos são produtos da organização social que estabelece relaçôes de poder sobre estratos da populaçáo que foram intencionalmente marginalizados. Para isso, valeram-se de critérios absolutamente arbitrários, elegendo o sistema de posses, a classe social, a raça, a etnia, o gênero, a orientação sexual, a deficiência e a idade como critérios de valoração de seres humanos.

O estabelecimento de "valores" tomando como base diferentes características das pessoas - o que compóe a diversidade humana - parte de princípios que ferem a ética e a moral. A falta de ética e a imoralidade de tais conceitos - que, inevitavelmente, resultam em preconceitos - no entanto, não bastou para que as instituiçóes historicamente não tomassem tais valores para o estabelecimento de uma estrutura de poder que permite açóes e atuaçóes que controlaram (e controlam), escravizaram (e escravizam) e mataram (e matam) pessoas pertencentes a esses grupos chamados minoritários, mas que aqui tratarei de minorizados. Minorizados por entender que houve uma intencionalidade que estruturou a sociedade da forma que conhecemos, em que grupos formados por homens ricos e brancos determinaram o curso da formação da sociedade capitalista.

Ao assumir o machismo como estrutural, não há espaço na sociedade que não padeça desse mal. Obviamente, ele também estrutura o meio esportivo e está presente nele, influenciando as suas várias dimensóes.

Minha intenção neste ensaio é narrar e analisar a experiência que tive ao acompanhar minhas filhas em competições de pólo aquático. As observaçóes e vivências me permitiram identificar vários elementos do machismo estrutural que permeiam o cotidiano deste esporte. 


\section{Desenvolvimento e discussão}

\section{Breve história do pólo aquático}

A análise histórica deste esporte já nos traz elementos que denotam a estrutura machista sobre a qual se fundou. Fruto da sociedade inglesa vitoriana e da revoluçáo industrial em meados da década de 1870, foi criado inicialmente como "futebol na água", praticado exclusivamente por homens. Em 1900, o polo aquático masculino foi introduzido nos Jogos Olímpicos ${ }^{1}$. A primeira competição mundial de polo aquático para mulheres foi organizada pela Fédération Internationale de Natation (FINA), em 1979². Somente cem anos depois do polo aquático ter sido reconhecido como modalidade olímpica, foi dado o direito às mulheres de participarem da competição, nos Jogos Olímpicos de 2000 em Sidney, Austrália ${ }^{3}$. Certamente, os reflexos dos cem anos de hegemonia masculina sobre a modalidade olímpica são sentidos no cotidiano das meninas e mulheres que praticam a modalidade atualmente.

Vale ressaltar que no momento em que a modalidade foi criada, no final do século XIX, as mulheres eram oprimidas e privadas de direitos, refletindo uma sociedade calcada na prática machista patriarcal. Este sistema permitiu que o Estado e a igreja estabelecessem domínio sobre as mulheres, fazendo prevalecer a desqualificação física e intelectual, colocando-as sob controle de homens que definiam as práticas sociais, culturais e políticas da época.

\section{O polo aquático brasileiro}

O polo se iniciou no Brasil no início do século XX. Há relato de que o primeiro jogo aconteceu em 1908, na praia de Santa Luzia. O time brasileiro de polo aquático masculino disputou os Jogos Olímpicos de 1920, 1932, 1960, 1964, 1968 e 1984. Em 2016, a modalidade participou com times masculino e feminino, por ter sediado os Jogos Olímpicos no Rio de Janeiro ${ }^{4}$

Não posso deixar de registrar um aspecto que permeia a prática de polo aquático no Brasil: uma endogenia de característica hereditária. Muitas e muitos atletas são filha(o)s ou neta(o)s de ex-atletas. Por conta da estrutura necessária para sua realização, a maioria dos times são formados por clubes de elite localizados no Rio de Janeiro e São Paulo. Apesar de haver cerca de trinta e um clubes filiados na Confederação Brasileira de Desportos Aquáticos $(\mathrm{CBDA})^{5}$, poucos oferecem formação ou têm times de polo aquático. Se considerarmos o acesso elitizado e a característica familiar na formação dos times, o polo aquático se tornou um esporte pouco divulgado e restrito a poucas pessoas.

Apesar do aspecto acima, devo mencionar pelo menos três iniciativas que tentaram romper a lógica elitista da modalidade:

a) O Programa Clube Escola, instituído pela Prefeitura Municipal de Sáo Paulo durante a gestão de Gilberto Kassab através do Decreto $n^{\circ} 48.392$, de 2007 ${ }^{\text {a }}$. O Programa buscava ampliar as atividades esportivas, garantindo acesso e inclusão por meio do uso de equipamentos esportivos da cidade, como o complexo do Pacaembu e os Centros Educacionais Unificados (CEUs), os quais muitos possuem piscina.

b) O Projeto Futuro da Associação Bauruense de Desportos Aquáticos (ABDA), criado em 2010 pelos empresários e irmáos Claudio Zopone e Claudenor Zopone Junior na cidade de Bauru. Em 2018, a ABDA fez parceria com o Governo do Estado do Rio de Janeiro e implantou projeto similar no Parque Aquático Júlio Delamare. $^{6}$

c) O Programa Atleta do Futuro do Serviço Social da Indústria (SESI), que busca a popularização e a formação de atletas do polo aquático. ${ }^{7}$

Os três programas visam a inclusão social de crianças e adolescentes através do esporte, em especial, de uma modalidade que, pela sua história e características, ficou reservada às elites. Houve avanço significativo na participação e diversidade no polo aquático a partir dos programas que agora, por conta da pandemia de Covid-19, estão ameaçados.

\section{A participaçáo e os direitos das mulheres}

Nos séculos XII e XIII, o movimento herético que produziu, portanto, hereges - permitiu razoável participação de mulheres, as quais podiam pregar, batizar e serem sacerdotisas. Havia comunidades formadas somente por mulheres e temas como aborto e métodos contraceptivos eram debatidos. No entanto, quando o controle sobre a reprodução passou a ser entendido como uma ameaça à 
estabilidade econômica e social, a figura do herege passou a ser cada vez mais atribuída a uma mulher ${ }^{8}$.

A tentativa de luta mais organizada que desafiava normas sexuais dominantes remonta à luta contra o feudalismo. As antigas servas do sistema feudal

[...] eram menos dependentes de seus parentes do sexo masculino, se diferenciavam menos deles física, social e psicologicamente e estavam menos subordinadas a suas necessidades do que logo estariam as mulheres 'livres' na sociedade capitalista (p. 51) ${ }^{8}$.

O entendimento de mulheres "livres" da sociedade capitalista vem acompanhado do entendimento de que o trabalho doméstico não é um verdadeiro trabalho. Portanto, as mulheres do sistema feudal na transição para o sistema capitalista já acumulavam trabalho nos campos e domésticos.

Paralelamente, a igreja trabalha sob a lógica da dominação e da violência, estabelecendo, por exemplo, a santificação do direito do marido bater em sua esposa, por meio de uma Lei Canônica.

No século XV, num projeto de cooptação de trabalhadores, instituiu-se na Europa uma política sexual, a partir do entendimento do domínio da sociedade através do sexo. O Estado buscava controlar trabalhadores oferecendo sexo como serviço e, portanto, estabelecendo domínio sobre os corpos das mulheres. Autoridades descriminalizaram o estupro quando as vítimas eram mulheres de classe baixa. Houve ainda institucionalização da prostituição. $\mathrm{O}$ bordel era considerado instituição do Estado e servia como remédio para a homossexualidade, por exemplo.

A perda expressiva de direitos das mulheres na Europa remonta aos séculos XVI e XVII, quando processos de degradação dos direitos das mulheres foram instituídos tanto como políticas na forma de leis, como no campo dos valores, estabelecendo estereótipos que colocavam por exemplo que

[...] as mulheres eram inferiores aos homens excessivamente emocionais e luxuriosas, incapazes de se governar - e que tinham que ser colocadas sob o controle masculino" (p. 201-202) ${ }^{8}$.

No século XVIII, após dois séculos de "caça às bruxas", as mulheres passaram a ser entendidas como seres passivos, desprovidas de atributos intelectuais, sexualidade ou vontade. Ainda no mesmo século, logo após a Revolução Francesa, Marie Gouze, também conhecida como Olympe de Gouges escreveu Déclaration des droits de la femme et de la citoyenne (Declaração dos direitos da mulher e da cidadã), em clara crítica à Declaração dos Direitos do Homem e do Cidadão de 1789 que continha apenas os direitos dos homens franceses. A declaraçáo e o guilhotinamento de Marie Gouze, em 1793, foram marcos importantes da luta das mulheres por direitos, o princípio do feminismo ${ }^{9}$.

$\mathrm{Na}$ Europa do final do século XIX, o uso da sexualidade como instrumento de dominação, a revolução industrial e o avanço do capitalismo, colocaram as mulheres em condição de absoluta subordinação. Tal condiçãao, contudo, não impediu que houvesse questionamentos e organização das mulheres as quais, naquele momento, entenderam que o principal ponto era a participação política.

A chamada primeira onda do feminismo se estabeleceu em torno do movimento sufragista entre o final do século XIX e início do século XX. No entanto, não foi somente a luta pelo direito ao voto que mobilizou as mulheres nesse período. Mulheres trabalhadoras também denunciavam suas condições, como fez a Uniâo das Costureiras, Chapeleiras e Classes Anexas em manifesto de $1917^{10}$.

A primeira onda do feminismo sofre uma guinada a partir da publicação de dois livros 'O segundo sexo', de Simone de Beauvoir, de 1949, e 'A mística feminina, de Betty Friedan, lançado em 1963. Os movimentos instalados a partir da década de 1960, nos quais as mulheres exigiam liberdade de escolha e autonomia, ficaram conhecidos como segunda onda do feminismo, que se estendeu até os anos 1990. Após esse período, o movimento feminista adquire conotação interseccional, pois passa a incorporar pautas que derivam da luta de classes, do movimento negro e LGBTQI+, influenciado por intelectuais como Lélia Gonzales e Angela Davis. A terceira onda do feminismo, como ficou conhecido, se estende até os dias de hoje, e busca ampliar a luta feminista. Como nos ensina Carla Akotirene: “... a interseccionalidade impede reducionismos da politica de identidade..." (p.59) ${ }^{11}$

\section{Mulheres no polo aquático}

É importante notar que, enquanto o polo aquático se estabelecia como instituição organizada a partir da sua inclusão como esporte olímpico nos primórdios do século XX, as mulheres lutavam por direitos basilares como o direito ao voto. Parece-me que, naquele momento, lutar por participação nos esportes era secundário, uma vez que havia pautas mais urgentes como direito à participação cidadã e ao trabalho e salário dignos, equiparáveis aos dos homens. 
O fato do primeiro campeonato mundial de polo aquático feminino ter acontecido no final da década de 1970 pode ser resultado das intensas mobilizaçóes e manifestações feministas desse período. Embora as principais reivindicaçóes tratassem das questôes culturais e liberdade sexual, como a contracepção, havia exigência de mais participação nas várias esferas da sociedade, inclusive nos esportes. No Brasil, é nesse período que há expressivo aumento da participação das mulheres nos Jogos Olímpicos. ${ }^{12}$

A participação das mulheres no polo aquático olímpico se deu após a terceira onda do feminismo, somente no início do século XXI. É emblemático o intervalo de cem anos entre o ingresso do polo masculino e o do feminino nos Jogos Olímpicos. Isso revela a dominação e hegemonia dos homens também nesse esporte, como no futebol de campo. ${ }^{13}$

Entre os anos de 2013 e 2019 acompanhei campeonatos de polo aquático no Brasil na condição de mãe de atletas. Foram muitas as situações as quais vivenciei e testemunhei que me permitem afirmar que o polo aquático brasileiro se fundou e continua funcionando sobre os pilares do machismo.

Antes de relatar o quanto o machismo interfere e afeta o cotidiano de meninas e mulheres no polo aquático, é preciso registrar que há uma lógica de opressão que domina o meio esportivo. A Educação Física, como disciplina, parte da educação do corpo, com influências militares e médicas, calcadas no conceito de aptidão física e esportiva, reprodutoras de práticas de dominaçãao ${ }^{14}$. Em outras palavras, o meio esportivo reproduz práticas e técnicas militarizadas, que buscam o disciplinamento dos corpos. Os métodos utilizados no processo de formação de atletas e nos treinos são, muitas vezes, práticas opressoras que se pautam pela desqualificação e, portanto, de violências, entre elas, a violência de gênero.

São muitos os exemplos trazidos pelas atletas que denotam as violências às quais estão submetidas: desqualificação física e intelectual, sexualização, racismo e abuso sexual ${ }^{\mathrm{b}}$. Cotidianamente, meninas e mulheres são expostas à intimidação e ao assédio de diversas ordens. O resultado desta prática perversa, que é de alguma forma aceita pela comunidade que acompanha o polo aquático - inclusive pais e máes, é a desistência e o afastamento da prática, especialmente das meninas e jovens que não compóem a elite aristocrática, aquela $\mathrm{da}(\mathrm{o})$ s descendentes do esporte como apresentado anteriormente.
No campo da gestáo e organização dos campeonatos, é nítida a lógica machista que ordena as decisóes. Os campeonatos são realizados pela CBDA e pela Liga Brasileira de Polo Aquático $(\mathrm{PAB})^{c}$. Constantemente, os campeonatos e os jogos são organizados priorizando os times masculinos, deixando os times femininos escanteados, em segundo plano. Exemplo dessa priorização é colocar jogos femininos em piscinas menos preparadas para a modalidade ou com dimensóes inadequadas e nos piores horários (último horário da noite e primeiro da manhã), chegando a prescindir da realização de jogos ou etapas de campeonatos para privilegiar o calendário de jogos masculinos.

A lógica machista não está posta somente na gestáo e organização dos jogos e campeonatos, mas em todos os níveis de participação, desde a arbitragem e corpo técnico até as diretorias das entidades reguladoras. Não há atualmente mulheres nas diretorias da CBDA e da PAB e, quando participam, são minoria ou ocupam funçóes $\mathrm{e}$ cargos subalternizados.

Devo destacar ainda aspectos que denotam a lógica machista também presente na divulgação da modalidade. Uma rápida passada pelas páginas e redes sociais da CBDA e da PAB basta para verificarmos que há maior peso na divulgaçáo de campeonatos masculinos, situação que foi apaziguada quando um grupo de pais e mães protocolou manifesto na CBDA e PAB em junho de 2018. Antes do manifesto, havia somente divulgação e promoção dos jogos e atletas do masculino. As homenagens são dadas quase exclusivamente aos atletas homens. As mais jovens precisam de referências femininas e há várias atletas brasileiras que se destacaram e se destacam dentro e fora do Brasil.

Embora haja menos clubes com times femininos, há empenho constante de atletas e ex-atletas para a manutenção da modalidade. A falta de incentivo para a formação de atletas para o feminino, assim como para a manutenção da modalidade é constante. A título de exemplo, por conta da pandemia de Covid-19, o SESI cortou os salários das atletas do polo aquático, mantendo os do time masculino. O resultado é que o time se desfez, o que pode levar as atletas a desistirem da modalidade caso náo encontrem oportunidades nos clubes de elite de São Paulo. Além da falta de incentivo financeiro, as meninas e jovens têm desistido da modalidade pelo conjunto de situações de intimidação, desqualificação e assédios que vivenciam no cotidiano de treinos e campeonatos. 


\title{
Considerações finais
}

É necessário que reconheçamos que o machismo estrutural está na gênese da sociedade contemporânea e, por isso, ele permeia todos os espaços de organizaçáo e participação social e política. Tal reconhecimento é essencial para que haja estabelecimento de açóes de combate ao preconceito, seja ele de qual origem for. Não há espaço na sociedade atual para o machismo, o racismo, o capacitismo, a xenofobia, o etarismo, a LGBTfobia ou qualquer tipo de preconceito que estigmatize e minore grupos de pessoas com características próprias de ordem física, intelectual, social, cultural ou psicológica.

O meio esportivo, em geral, perpetua práticas opressoras que, através de seus métodos militarizados ainda predominantes, impactam negativamente atletas e modalidades esportivas. Apesar da opressão estar presente em muitas modalidades, tanto masculinas quanto femininas, os grupos minorizados são mais comumente atacados. Mulheres, pessoas negras, LGBTQIA+ e com deficiência são, assim como na sociedade, os grupos que mais sofrem com a violência e a opressão.

Esse ensaio buscou mostrar, usando o polo aquático como exemplo, o quanto a lógica machista está presente no meio esportivo. Se tomarmos o termo toxina como algo gerado por um ser vivo capaz de causar danos a outro ser vivo, o machismo, produto histórico-cultural da sociedade contemporânea, é um elemento que degrada relaçóes no meio esportivo e, portanto, degrada o próprio meio. Enquanto não eliminarmos a toxina do machismo, o meio estará comprometido!

\section{Notas}

a. Disponível em: http://legislacao.prefeitura.sp.gov.br/leis/decreto-48392-de-29-de-maio-de-2007.

b. Disponível em: https://www1.folha.uol.com.br/esporte/2019/04/em-denuncia-ao-cob-atleta-diz-que-foi-assediada-portecnico-do-polo-aquatico.shtml?origin=uol.

c. Fundada com a participação de dez clubes em março de 2016: Club Athletico Paulistano (SP), Clube Jundiaiense (SP), Clube Paineiras do Morumby (SP), Clube de Regatas do Flamengo (RJ), Esporte Clube Pinheiros (SP), Tijuca Tênis Clube (RJ), Fluminense Football Club (RJ), Clube Internacional de Regatas (SP), Associação Brasileira "A Hebraica” de São Paulo (SP) e Serviço Social da Indústria - SESI-SP (SP).

\begin{abstract}
Misogyny: the toxin that degrades the sporty environment

Misogyny and the oppression originated in the structure of the society and is, therefore, intrinsically structural. Structural misogyny permeates in many spheres of social and political organization, including the sports environment. In this essay, I have aimed to bring some aspect of the genesis of misogyny and violence against women to light estabilish relationships with some facts personal experiences within Brazilian water polo. The everyday life of the athletes of this modality reveals a toxic and opressive environment which reproduces the violence against girls and women. The lack participation of women in the spheres of decision making an agravant factor. It is necessary to recognize the presence of systemic misogyny in sports, and consider actions to combat this oppressive practice.
\end{abstract}

KEYWORDS: Water polo; Oppression; Violence; Women. 


\section{Referências}

1. Fina. Fédération Internationale de Natation. Disponível em: https://learning.fina.org/45268-2/. Acesso em: 30 dez 2020.

2. History of the Game of Water Polo. Disponível em: https://collegiatewaterpolo.org/fans/gameinfo/ history/\#: : :text=The\%20first\%20Water\%20Polo\%20World,the\%20Soviet $\% 20$ Union $\% 20$ and\%20Hungary. Acesso em: $30 \mathrm{dez} 2020$.

3. The Olympic Studies Centre. History of Water Polo at the Olympic Games. Disponível em: https://stillmedab.olympic. org/media/Document\%20Library/OlympicOrg/Factsheets-Reference-Documents/Games/OG/History-of-sports/Referencedocument-Aquatics-Water-Polo-History-at-the-OG.pdf\#_ga=2.213079383.2937780.1609337334-485031816.160933733. Acesso em: $30 \mathrm{dez} 2020$.

4. Liga Brasileira de Polo Aquático. Disponível em: https://ligapab.com.br/memoria/. Acesso em: 4 jan 2021.

5. Confederação Brasileira de Desportos Aquáticos. Disponível em: https://cbda.org.br/br/poloaquatico/clubes. Acesso em: 4 jan 2021.

6. Associação Bauruense de Desportos Aquáticos. Disponível em: https://abdabauru.com.br/sobre-o-projeto/. Acesso em: 4 jan 2021.

7. Serviço Social da Indústria. Disponível em: https://www.sesisp.org.br/esporte/esporte/polo-aquatico\#:-:text=Os\%20 atletas\%20do\%20SESI\%2DSP,Internacional\%20de\%20Nata\%C3\%A7\%C3\%A3o\%20(Fina). Acesso em: 4 jan 2021.

8. Federici S. Calibã e a bruxa: mulheres, corpo e acumulação primitiva. Traduçáo: coletivo Sycorax. São Paulo: Elefante; 2017.

9. Farias Monteiro K, Grubba LS. A luta das mulheres pelo espaço público na primeira onda do feminismo: de suffragettes às sufragistas. Direito e desenvolvimento [Internet]. 2017;8(2):261-78. Disponível em: https://periodicos.unipe.br/index.php/direitoedesenvolvimento/article/view/563. Acesso em: $30 \mathrm{dez} 2020$.

10. Pinto CRJ. Feminismo, história e poder. Rev Sociol Política. 2012;18(36):15-23.

11. Akotirene C. Interseccionalidade. São Paulo: Pólen; 2019.

12. Goellner S. Mulher e esporte no Brasil: Entre incentivos e interdiçôes elas fazem história. Pensar Prát. 2005;8. Disponível em: 10.5216/rpp.v8i1.106. Acesso em: $30 \mathrm{dez} 2020$.

13. Batista RS, Devide FP. Mulheres, futebol e gênero: reflexôes sobre a participação feminina numa área de reserva masculina [Internet]. Efdeportes. 2019;14(137). Disponível em: https://www.efdeportes.com/efd137/mulheres-futebol-e-genero. htm. Acesso em: 4 jan 2020.

14. Bracht V. A constituição das teorias pedagógicas da educaçáo física. Cad CEDES. 1999;19(48):69-88.

\begin{tabular}{r|r} 
ENDEREÇO & \\
Profa. Dra. Michele Schultz & \\
Universidade de São Paulo & \\
Escola de Artes, Ciências e Humanidades & Recebido: 04/ 01/2021 \\
Campus Cidade Universitária & Aceito: 06/01/2021 \\
Rua Arlindo Bettio, 1000 & \\
03828-100 - São Paulo - SP - Brasil & \\
E-mail: mschultz@usp.br &
\end{tabular}

